\title{
Industrias culturales y globalización: Procesos de desarrollo e integración en América Latina
}

\section{Néstor García Canclini}

Tres tendencias caracterizan la situación latinoamericana respecto de este tema. En primer lugar industrias culturales han pasado a ser los actores predominantes en la comunicación y en la formación de la esfera pública. También ocupan, dentro de cada sociedad, un lugar más significativo que las manifestaciones artísticas y culturales tradicionales en la actividad económica para las altas inversiones que movilizan la generación de empleos y el intercambio económico y simbólico con otras naciones. Sin embargo, el tercer rasgo es contradictorio con los dos anteriores: en estos mismos años en que las industrias culturales ganan un lugar central se reduce la producción editorial, y cinematográfica de los paises latinoamericanos y se transnacionaliza la propiedad de los medios de producción. En la publicación de libros, Argentina y México han debilitado sus industrias mientras empresas transnacionales con base en España se convierten en protagonistas del mercado regional en cine, televisión y música, salvo Brasil y México, las importaciones prevalecen cada vez más sobre la producción endógena y sobre la capacidad exportadora de los países latinoamericanos.

Este trabajo interprefa que la privatización y transnacionalización de las industrias culturales, y la desresponsabilización de los Estados respecto de ellas, ha generado una declinación de la vida pública y de la representación de las sociedades nacionales en los medios de comunicación. Propone replantear las políticas culturales superando el horizonte de lo micropúblico localo nacional y buscando modos de acción en las esferas meso y macropúblicas (nacional y transnacional).

Por una parte, es necesario reequilibrar la enorme asimetría entre el alto consumo de medios audiovisuales e informativos en América Latina y la baja producción propia. Al mismo tiempo, es preciso reconsiderar lo que se concibe coma cultura propia (nacional o latinoamericana) teniendo en cuenta su recomposición en tiempos globalizados y lo que hoy entienden los consumidores por interés público y calidad de vida. 
La revalorización de la vida pública asociada a un resurgimiento de las industrias culturales latinoanericanas no ocurrirá sin una revitalización del papel cle Estado, no tanto como propietario de los medios sino como coparticipante y regulador junto con la sociedad civil. Dado que la esfera pública y la cildadana se desarrollan ahora con un horizonte transnacional, los organismos supranacionales (UNESCO, BID, OEA, Convenio Andrés Bello, SELA, Mercosur) pueden cumplir un papel decisivo para que las interacciones comerciales se relacionen con otras interacciones sociales y culturales donde se gestiona la calidad de vida y' que no son reductibles al mercado, como los derechos humanos, la innovación cienrífica y estética, la participación social, la preservación de patrimonios naturales y sociales, las reivindicaciones de mayorías y minorías.

El texto propone un conjunto de acciones para contribuir a crear culturalmente el espacio público de la integración latinoamericana; crear un Sistema Latinoamericano de Información Cultural que produzca y reúna estadísticas confiables; promover dispositivos que articulen a los sectores estatal, privado y asociativo para generar diagnósticos de las necesidades socio-culturales de la población y estudios que valoren el papel económico de las industrias culturales en relación con las necesidades del consumo y de la ciudadanía; realizar estudios comparativos de los mecanismos públicos y mixtos de financiamiento de la cultura; propiciar la creación de Consejos Nacionales de Industrias Culturales.

El dilema decisivo hoy en las culturas latinoamericanas no es definir las identidades o globalizamos, sino integrar sólo capitales y dispositivos de seguridad o construir la unidad solidaria de ciudadanos y sociedades que reconocen sus diferencias.

Este texto trata de caracterizar el papel de las industrias culturales en la globalización, con especial referencia al desarrollo sociocultural de América Latina en las dos últimas décadas. Voy a describir algunas tendencias generales, luego presentaré breves análisis diferenciados en cada industria cultural. Por último, quiero sugerir cómo sería necesario repensar la esfera pública y la ciudadana en relación con la integración latinoamericana. 
a) La primera tendencia global es que las industrias culturales han pasado a ser los actores predominantes en la comunicación social y en la constitución de la esfera pública. En la formación de las naciones latinoamericanas la literatura, las artes visuales y la música proporcionaron los recursos culturales para las reflexiones fundacionales, la elaboración discursiva sobre lo que se llamaba «el ser nacional» y las imágenes que emblematizaban la identidad de cada nación: de Sarmiento y Arguedas hasta Neruda, Paz y Borges, desde el muralismo mexicano y boliviano hasta el tango y el folclore andino. Sólo la radio comenzó a desempeñar este papel unificador de las sociedades nacionales antes de la mitad de siglo, y el cine en los países que lo tenían (Argentina y México). Pero la estructura del desarrollo cultural cambia a partir de los años cincuenta con el surgimiento de la televisión, la expansión masiva de la radio en los mismos años y luego el vídeo y la informática desde mediados de los 80 .

Un sector creciente de la producción cultural se realiza en forma industrializada, circula en redes transnacionales de comunicación y es recibida por consumidores masivos que aprenden a ser públicos de mensajes desterritorializados: lo que un antropólogo brasileño, Renato Ortiz, denomina «un folclore internacional-popular». Las comunidades internacionales de espectadores reducen la importancia de las diferencias nacionales. Sobre todo las generaciones jóvenes guían sus prácticas culturales de acuerdo con información y estilos homogeneizados, captables por los receptores de diversas sociedades con independencia de sus concepciones políticas, religiosas o nacionales. Los consumidores de diferentes clases sociales son capaces de leer las citas de un imaginario multilocalizado que la televisión y la publicidad agrupan: los ídolos del cine hollywoodense y de la música pop, los diseños de pintores famosos, los héroes deportivos y los políticos de varios países componen un repertorio de signos en constante disponibilidad.

Los cambios que están ocurriendo en la cultura desde mediados de este siglo, especialmente desde los años sesenta a la actualidad, pueden condensarse en la diferencia entre internacionalización y globalización. La internacionalización de las economías y las culturas, desarrollada a lo largo de la modernidad, consistió en abrir las fronteras geográficas de cada sociedad para incorporar bienes y mensajes de otras. En un período de globalización, en cambio, se produce une interacción funcional de actividades económicas y culturales dispersas, generadas por un sistema con muchos centros, en el que son más decisivas la velocidad para recorrer el mundo y las estrategias para sedu- 
cir a los públicos que la inercia de las tradiciones históricas locales (Appadurai, Arizpe, Castells, Hannerz, Ortiz).

Sin duda, este proceso es más claramente perceptible en los circuitos de comunicación electrónica. Pero abarca, en cierta medida, casi todas las áreas de desarrollo cultural, incluso las artes y artesanos tradicionales. Como consecuencia, recoloca el sentido de los actores mencionados: los Estados nacionales, las iniciativas privadas y los organismos independientes.

b) Una segunda tendencia, derivada de la anterior, fue que la cultura pasó a tener un lugar prominente y estratégico en el desarrollo socioeconómico. Cuando se pensaba que la cultura consistía en libros y cuadros se los podía concebir como aspectos suntuarios de la vida social, ocupaciones de fin de semana, insignificantes en las cuentas económicas de la nación. En la actualidad los movimientos mundiales de la industria musical alcanzan los $40 \mathrm{mil}$ millones de dólares, 90 por ciento de los cuales se concentran en las seis mejores: BMG, EMI, SONY, Warner, Polygram y Universal (Yúdice). Las exportaciones de la industria audiovisual constituyen el segundo rubro en ingresos por exportaciones de la economía norteamericana, luego de la industria aerospacial. En Estados Unidos el sector cultural, sobre todo por la producción y exportación audiovisual, representa el $6 \%$ del producto interno bruto y emplea a 1,3 millones de personas, más que la minería, la policía o la forestación. En Francia abarcaba en 1992 el $3.1 \%$ del PIB. En los países latinoamericanos más desarrollados, como Argentina, Brasil, Colombia y México, la producción y la venta de discos y libros, de equipamientos culturales y de entretenimiento, de telenovelas y videos, creció en forma impresionante desde los años 70, constituyendo un mercado de bienes simbólicos tan significativo como el de otros productos. Brasil, que ocupa el sexto lugar en el mercado mundial de discos, factura más de 800 millones de dólares por año (Alvarez). Pese a los altibajos de algunas ramas, por ejemplo la industria editorial y la de cine, el conjunto de la producción cultural constituye un importante campo de inversión, circulación de capital y generación de empleos.

Durante la década de los noventa, los acuerdos de libre comercio (TLC, Mercosur, etc.) han vuelto más patente la importancia económica de las comunicaciones masivas y su papel como instrumento de conocimiento recíproco, integración y segregación entre las naciones. Aún en los casos en que los tratados de liberalización comercial no incluyen a la cultura en la agenda de negociación, como el firmado entre México, Estados Unidos y Canadá, la 
intensificación de los intercambios está favoreciendo convenios entre empresas editoriales y de televisión de esos países.

Los cambios económicos se acompañan con modificaciones de las imágenes que unas sociedades tienen de otras. Estas representaciones culturales condicionan la disposición y las dificultades de los intercambios económicos. A ella se agrega la internacionalización de la producción cultural, que genera nuevos desafíos: necesidad de diseñar políticas que promuevan y regulen la producción y la comercialización de la cultura más allá de las fronteras nacionales, acuerdos sobre aranceles, propiedad intelectual, e inversiones extranjeras y multinacionales, derechos de los consumidores y otras cuestiones en las que está casi todo por hacer en el continente latinoamericano.

c) Una tercera característica de este proceso es que, en los mismos años en que las industrias culturales pasaron a ocupar este lugar central en el mundo, se fue perdiendo en los países latinoamericanos capacidad de producción endógena. En parte, esto se debe a la estructura oligopolista y al alto nivel de concentración de la producción industrial de cultura, que da al mundo anglosajón, y sobre todo a Estados Unidos, los mayores beneficios. La asimetría también se acentúa por la reducción de las inversiones estatales en América Latina, la transnacionalización de la propiedad de los medios y la expansión de consumo en una franja muy estrecha de la población. Tres advertencias: a) esto no ocurrió sólo por la transnacionalización de la cultura y la economía; b) no sucedió del mismo modo en todas las industrias culturales; c) no ocurrió de igual manera en todos los países. Para comprender estas diferencias voy a describir la situación en cada una de las principales áreas culturales.

\section{La cultura latinoamericana en la recomposición de los mercados transnacionales}

\section{1.- La industria editorial}

¿Qué queda de la vasta producción de libros y revistas que hubo en Argentina, México y algunos otros países latinoamericanos entre los años 1940 y 1970?. En parte por su propio liderazgo económico y cultural, en parte con el impulso de exiliados españoles, estos países publicaron lo que escribían los principales autores de toda América Latina y muchos de España. Además, 
tradujeron un alto número de libros europeos, norteamericanos y algunos asiáticos. Fue en este campo donde nuestro continente logró en términos económicos, literarios y periodísticos, una participación más intensa en la circulación internacional de bienes culturales. Además, ese desarrollo editorial fue importante en la formación de una ciudadanía ilustrada.

La declinación de las economías de esta región en las últimas dos décadas y el avance español en el mismo período modificaron esa situación. Argentina y México producen menos de 10.000 títulos por año, en tanto España supera los 50,000. Se han cerrado editoriales y librerías, muchos diarios y revistas quebraron o redujeron sus páginas. Unas 400 empresas editoriales mexicanos cerraron a partir de 1989, y entre las sobrevivientes no llegan a diez las de capital nacional que publican más de 50 títulos por año (Citesa, Era, Esfinge Fernández, Fondo de Cultura Económica, Limusa, Porrúa, Siglo XXI y Trillas). El aumento internacional del precio del papel, agravado por la devaluación de peso mexicano, es una de las causas de este retroceso. Otros motivos son la reducción general de consumo por la pauperización de las clases medias y populares, y la conversión de los libros en simples mercancías, sin los beneficios arancelarios ni la exención de impuestos que tuvieron en otro tiempo.

¿Puede el desarrollo del libre comercio favorecer un relanzamiento de las editoriales latinoamericanas? En rigor, la liberalización comercial de este campo en México comenzó hace veinte años. Fueron las editoriales españolas las que más aprovecharon la apertura económica para traer sus productos al mercado mexicano, asociarse con editoriales nacionales o directamente comprarlas. Por la comunidad de lengua y tradiciones culturales, España parece seguir siendo el interlocutor comercial que más puede beneficiarse en el futuro. Aunque la situación se ha complicado por la «europeización» de la industria española varias casas editoras de Madrid y Barcelona que habían comprado editoriales mexicanas fueron a su vez absorbidas en la década del ochenta por empresas de otros países europeos (Anaya adquirió a Alianza, Labor y Nueva Imagen; Mondadori a Grijalbo; Planeta a Ariel y Seix Barral, el grupo Berstelman a la Editorial Sudamericana).

Se observan cambios también originados por el Tratado de Libre Comercio entre México, Estados Unidos y Canadá, que comenzó a aplicarse en 1994. Varias editoriales estadounidenses, por ejemplo Mc Graw Hill y Prentice Hall, han entrado al mercado mexicano con diccionarios, libros de texto de secun- 
daria, para universidades, y libros «de superación personal». Algunos editores suponen que la incidencia futura de los empresarios estadounidenses no se producirá tanto en la generación de nuevas casas editoras como en el proceso de producción: papel, maquinaria, y, como ya ocurre, ediciones de alta calidad (color, pasta dura), para lo cual disponen de infraestructura y personal más calificado (Alatriste; García Canclini, 1996).

Hay datos indicativos de que el acercamiento actual entre México y EU puede suscitar tantos cambios en el mercado editorial estadounidense como en el mexicano. La novela de la mexicana Laura Esquivel, «Como agua para chocolate», superó el millón de ejemplares en inglés. Y además vendió 200.000 ejemplares en español, en EU. Libros de García Márquez, Carlos Fuentes y Julio Cortázar se venden en tiendas de autoservicio de Nueva York, California y Texas. Por primera vez existe en EU un mercado de derechos de autor en lengua española. Así como la sección de «música latina» creció en Tower Record y otras cadenas importantes, los títulos de origen español mas vendidos comparten sitios preferentes con los best seller en inglés. Los escritores chicanos contribuyen a este reconocimiento a «lo latino». La «americanización» de América Latina se compensa, en alguna medida, con la latinización de Estados Unidos. Pero salvo unas pocas transnacionales, ni las editoriales ni los gobiernos latinoamericanos han generado programas para aprovechar estas oportunidades.

¿Cómo se desarrolla la circulación de libros mexicanos y argentinos en América Latina, mercado «natural» por la lengua, los intereses históricos compartidos y los estilos de consumo de los lectores? Las ventas se han visto reducidas por las dificultades económicas y políticas de toda la región. EI único país donde el gobiemo impulsa con decisión la industria editorial es Colombia: la Ley de libro promulgada en 1993, que libera de impuestos por veinte años a los editores residentes en ese país y les garantiza la compra del 20 por ciento de todas sus ediciones para bibliotecas está fomentando el desarrollo de una sólida industria editorial con capitales transnacionales y creciente capacidad de exportación. En los demás países la legislación es anacrónica, y son más las trabas para la circulación de libros y revistas que los programas de promoción de la producción, la difusión y la lectura.

En tales condiciones, siguen vigentes las propuestas de Cerlalc, organismo de la UNESCO para el libro latinoamericano, acerca de las medidas necesarias para fortalecer el intercambio regional, algo así como un «mercado 
común latinoamericano del libro»: desgravación de insumos para el sector editorial (y en particular libre tránsito de negativos con contenido editorial); facilitar la importación de equipos para la industria gráfica; abatir costos con tirajes amplios y reforzar las coediciones intrarregionales; suprimir toda clase de aranceles y otras trabas no arancelarias para la circulación de libros; mejorar y abaratar los medios de transporte (aéreo marítimo y postal); dar incentivos a la exportación y créditos a la importación de libros; adherir plenamente a los convenios internacionales de protección a la propiedad intelectual; definir políticas nacionales del libro, unificar la legislación correspondiente y crear organismos rectores, en donde están bien representados los intereses sociales y privados del sector editorial.

\section{2.- Televisión, cine y vídeo: hacia una cultura multimedia}

Partamos de lo que ha ocurrido con el medio audiovisual que recorrió todo el siglo veinte: el cine. Sus transformaciones en los modos de producir y en el acceso de los públicos revelan el tipo de recomposición multimedia que ha ocurrido en el campo audiovisual. Se ha hablado y publicado mucho sobre «la muerte del cine». Pero las cifras revelan que actualmente se ven más películas que en cualquier época anterior. Lo que ocurre es que se ven en la casa: en televisión o en vídeo. De los 16 millones de hogares mexicanos, más de 13 millones cuentan con televisor y más de 6 millones con videocasetera. Existen 9,500 videoclubes distribuidos en todo el país, incluso en zonas populares y en pequeños pueblos campesinos que amplían el acceso a la oferta cinematográfica. Una expansión semejante de los entretenimientos audiovisuales a domicilio se observa en los demás países de América Latina, aunque en algunos casos -el más notorio es Argentina- la televisión por cable se convierte en el negocio más próspero: actualmente, más del 60 por ciento de los hogares de este país cuenta con dicho servicio.

En conjunto, América Latina está mal colocada en el aprovechamiento productivo de estos nuevos circuitos comunicacionales. La producción de películas ha caído durante la década del noventa en Argentina, Brasil y México; y es poco significativa en otros países. Aún peor es lo que sucede en la exportación. Los países latinoamericanos transmiten en promedio más de 600 mil horas anuales de televisión: en Colombia, Panamá, Perú y Venezuela hay más de una videocasetera por cada tres hogares con televisión, propor- 
ción más alta que en Bélgica (26.3\%) o Italia (16.9\%) (Roncagliolo). Pero una pequeñísima parte de la producción latinoamericana de cine se halla en vídeo. Somos subdesarrollados en la producción endógena para los medios electrónicos, pero no en el consumo audiovisual.

Esta asimetría entre una producción propia débil y un consumo elevado, se manifiesta como una baja representación en las pantallas de las culturas nacionales o latinoamericanas y una enorme presencia de entretenimientos $\mathrm{e}$ información originados en EU. Pero este desnivel no es igual en todas las sociedades. Deben distinguirse, como lo hace Rafael Roncagliolo, los países exportadores e importadores. En verdad, sólo dos, Brasil y México, están «incorporados a la economía global de bienes culturales, y son sedes de gigantes del audiovisual, Red Globo y Televisa respectivamente». «Globo es básicamente un exportador de audiovisuales, que condujo a Brasil al cuarto lugar como productor y tercero como exportador audiovisual, pero no ha transnacionalizado su producción; Televisa, en cambio, actúa en la región como una genuina corporación transnacional, que compra canales e internacionaliza sus actividades productivas» (Roncagliolo).

Luego, hay unos pocos países «incipientemente exportadores»: Argentina, Venezuela, y en menor medida Colombia, Chile y Perú. Como afirma el mismo autor, estos países tienen una situación ambigua, «pues por un lado están buscando mercados para su producción cultural y, por el otro, tienen que defenderse frente a la penetración, ya no sólo de las empresas extra-regionales, sino de las propias transnacionales latinoamericanas, como Televisa».

En tercer lugar, se encuentra el resto de los países, «netamente importadores», donde la casi totalidad de los mensajes proceden de Estados Unidos. Aunque aún donde se cuenta con mayor producción propia, como en la televisión brasileña, mexicana y argentina, más del 70\% de las películas y series son importadas de EU, y los programas de este país ocupan más del 50\% de prime time. La producción nacional se dedica sobre todo a noticiarios, que por lo tanto es la franja más cercana a los intereses cotidianos de la audiencia, en tanto los programas de entretenimiento tienen una composición importada mayor.

El desequilibrio entre la débil producción endógena y el consumo crecientemente importado se acentúa en la medida en que los medios masivos «clásicos» (radio, cine, televisión) se integran en autopistas de la comunicación. A este proceso de concentración tecnológica se agrega la reorganización monopólica de los mercados que subordina los circuitos nacionales a 
sistemas transnacionalizados de producción y comercialización.

Todo esto adquiere importancia no sólo por su significado cultural. Las industrias comunicacionales se colocan entre los agentes económicos más dinámicos, principales generadores de inversiones y empleos, o sea que ocupan un lugar clave como impulsoras de desarrollo y de los intercambios multiculturales. Por eso, es crucial la pregunta de quienes van a manejar estas redes en los próximos años. La producción audiovisual de información y entretenimiento está mayoritariamente en manos estadounidenses mientras el $70 \%$ de las ventas mundiales de aparatos electrónicos para el gran público es controlado por firmas japonesas.

\section{Reencontrar al público en la cultura globalizada}

A medida que las industrias culturales se apropiaron de la mayor parte de la vida pública, han experimentado un proceso de privatización, transnacionalización y desresponzabilización respecto de los intereses públicos en la vida social. ¿Cómo elaborar políticas culturales que vinculen creativamente a las industrias culturales con la esfera pública de acuerdo con la lógica de la actual etapa de globalización e integraciones regionales? No nos sirven los esquemas conceptuales empleados en la época en que las relaciones internacionales se entendían en términos de imperialismo, dependencia y culturas nacionales con relativa autonomía.

Tenemos que preguntarnos cómo se reformulan la esfera pública y la ciudadanía a escala transnacional. Un primer cambio es, justamente, que lo público se está rehaciendo en relación con las industrias culturales. Los análisis históricos demuestran que esta noción atravesó la modernidad con diversos significados. En los siglos XVIIT y XIX europeos, en América Latina durante el siglo pasado y buena parte del actual, la esfera pública fue concebida como un espacio desde el cual luchar contra los Estados despóticos, contra los abusos y arbitrariedades de los monarcas y dictadores que sometían la vida social y económica a sus intereses privados. Luego, se erigió lo público como defensa de la social frente a la voracidad monopólica de las empresas capitalistas, las amenazas que esto representaba para la libre comunicación entre ciudadanos y los riesgos de reducir la participación social a prácticas de consumo (Arendt, Habermas). En un tercer momento, desde mediados de este si- 
glo, la importancia adquirida por la radiodifusión como servicio público llevó a pensar este tipo de comunicación como modelo de una esfera pública de ciudadanos que deliberan con independencia de poder estatal y del lucro de las empresas (Garnham). Es innegable que estas maneras de defender lo público generaron espacios emancipatorios, donde crecieron la información independiente y la conciencia ciudadana, se legitimaron las demandas de la gente común y se limitó el poder de los grupos hegemónicos en la política y los negocios.

Sin embargo, estas concepciones y sus aportes al proceso emancipatorio están siendo problematizados por varias razones: a) la recomposición de la esfera pública dentro de cada país y el cuestionamiento de las formas clásicas de representatividad (partidos, sindicatos, movimientos sociales, iglesias), tema sobre el cual no puedo extenderme aquí pero que sabemos afecta también la capacidad representativa de los medios comunicacionales públicos; b) la reducción del papel de los Estados como proveedores de servicios públicos y el estrechamiento de sus recursos financieros en un período en que las innovaciones tecnológicas y el encarecimiento de la producción comunicacional exigen altas inversiones, que son más accesibles al sector privado: las iniciativas de renovación y expansión dejan de estar en manos de la British Broadcasting Company (BBC), de la RAl Italiana, y de los medios estatales o paraestatales semejantes en Europa y América Latina, que ceden ese papel a Murdoch, Berlusconi, CNN, Globo y Televisa: c) aumento de la competencia transnacional por los mercados y la innovación tecnológica, que subordina a la rápida acumulación mercantil, las tareas culturales y la responsabilidad informativa, llevando incluso a la «autocomercialización» a las radios y los canales de televisión públicos; d) el reordenamiento de la esfera pública a escala multinacional gracias a las redes tecnológicas (televisión por cable y vía satélite, circuitos computacionales), cuya «geografía» trasciende los territorios nacionales y la vigilancia de los Estados; e) la transferencia de funciones clásicas de los aparatos comunicacionales y de política cultural de los Estados nacionales a radios comunitarias y televisores regionales.

Cuando la esfera pública ya no se deja abarcar en el ámbito de cada nación, es necesario ampliar el análisis de lo público, más que como un espacio, como circuitos y flujos que articulan, lo nacional y lo global, John Keane define la esfera pública como «un tipo particular de relación espacial entre dos o más personas, usualmente vinculadas por algún medio de comunicación (televisión, radio, satélite, fax, teléfono, etc.), en la cual se producen contro- 
versias no violentas, durante un tiempo breve o más extendido, referidas a las relaciones de poder que operan dentro de su medio de interacción y/o dentro de los ámbitos más amplios de estructuras sociales y políticas en las cuales los disputantes están situados» (Keane, 8)

¿Cómo interactúan, los contendientes de diferentes escalas geográficas y comunicacionales? Hay que distinguir primero, según este autor, esferas micropúblicas espacios locales en los que intervienen decenas, centenares o miles de participantes. Son ejemplos las reuniones de vecinos, una iglesia, cafeterías y por supuesto movimientos sociales que funcionan corno laboratorios locales de comunicación ciudadana. Keane menciona también un caso menos convencional: los grupos de niños que se organizan en torno de los videojuegos para utilizarlos e intercambiarlos, «crean una cultura cotidiana de historias que se narran en el salón de clases» y comparten un lenguaje que los diferencia de los adultos. Las polémicas acerca de si los videojuegos provocan adicción a una visualidad frívola y banalizan la violencia contra mujeres o minorías o, en cambio, enseñan la interactividad, afinan la coordinación entre la vista y las manos, y habitúan a codeterminar los resultados de un juego mediado electrónicamente, apuntan a algunos nuevos dilemas en que se debate la recomposición tecnológica y audiovisual de lo público (Sarlo).

En segundo término, las mesoesferas públicas aluden a la dimensión del Estado-nación, en que millones de personas debaten sobre el poder a través de diarios de circulación nacional (New York Times, Le Monde, A Folha de Sao Paulo, Clarín, El País) y medios electrónicos con alcance semejante. En los últimos años, el predominio de estos medios sobre la comunicación local, y su administración por empresas privadas, muestra el declinante papel de los «servicios públicos» o paraestatales y la hegemonía de actores privados en las controversias sobre el poder. La irrupción en la vida política de figuras como Silvio Berlusconi señala los extremos más inquietantes de esta tendencia. Pero su estrategia más frecuente no consiste en apoderarse directamente de la escena pública, sino en intervenir en ella mediante la publicitación de escándalos políticos y familiares. A veces, esta acción mediática contribuye a transparentar el campo político, pero su finalidad preponderante es aumentar la audiencia y el éxito comercial de estos medios. Primero en la televisión y ahora también en los diarios esta reorganización de los vínculos entre lo público y lo privado ha cambiado el sentido de la vida pública el desplazarla del debate argumentado a las narrativas espectacularizadas. 
Los procesos de globalización e integración regionales llevan a reconocer también la existencia de lo macropúblico. A las agencias de noticias que desde hace décadas cubren todo el planeta, se agregan las transnacionales multimedia (Time-Warner, Bertelsman). Si bien éstas se expandieron, según Keane, como un fenómeno de la economía política más que con el fin de reorganizar el ámbito público, de hecho su modo de concentrar el talento periodístico y creativo, las innovaciones tecnológicas y los canales de difusión, las convierte en los grandes administradores de la información y el entretenimiento mundial. La fluida comunicación global impulsada por este proceso establece comparaciones constantes entre los «estándares de vida» de regiones y países alejados, propicia debates públicos transnacionales (aunque los hechos ocurran en uno a dos países) como se vio en las guerras de las Malvinas y del Golfo, las crisis financieras de México y del sureste asiático. Pasamos de la cámara de diputados y la televisión nacionales al mundo de la comunicación por satélite como escena deliberativa. Los cambios se producen tanto en los macroagentes comunicacionales como en los emisores locales, y por supuesto en la recepción: las cámaras que filman los acontecimientos globales encuentran que desde los estudiantes chinos en la Plaza de Tiananmen hasta los zapatistas en la selva de Chiapas los reciben con pancartas en inglés para ser comprendidos en todas partes.

Al mismo tiempo que los referentes identitarios se citan en escenas nacionales e internacionales, en las disputas ciudadanas y en las prácticas de consumo, también lo público, entendido en parte como los lugares y circuitos en que se delibera sobre la vida social, trasciende el Estado-nación. Keane tiene razón al decir que ni siquiera las primeras esferas públicas modernas se limitaban al ideal habermasiano de la discusión racional; también se desenvolvían en formas de comunicación como la ópera, los deportes y las artes visuales. Los cambios recientes hacen aún más evidente que lo público se desarrolla tanto en los diarios y la radiodifusión como en los entretenimientos, no sólo en los medios bajo control estatal o concebidos como servicio público sino también en los talk shows televisivos, los videojuegos, los concursos en que se premian éxitos personales y habilidades como si fueran desempeños públicos. En relación con el propósito de este texto, diré que -así como la antropología demostró hace tiempo que todo esto es cultura- la nueva reflexión sobre lo público y la ciudadanía lleva a reconocer que estos diversos circuitos deben ser competencia de la política cultural. 
Es necesario avanzar más allá de esta valiosa propuesta de Keane. La fascinación con la globalización de las comunicaciones no puede hacernos descuidar la persistencia de viejas asimetrías y desigualdades, y la producción de otras nuevas, entre ciber-ricos y ciber-pobres, entre informados y entretenidos. Es cierto que más que la radio y la televisión, las comunicaciones electrónicas -especialmente Internet- están volviendo más horizontales y recíprocas las comunicaciones. En la esfera pública supranacional se pueden acentuar los aspectos electivos y contractuales de la participación social y política en la medida en que las tecnologías recientes faciliten que las controversias, la defensa de los derechos humanos y la circulación de la información que sirve para innovar y tomar decisiones se efectúen en redes de «netizens», ciudadanos que enlazan sus privacidades en la construcción de nuevos desempeños públicos. Pero ni siquiera en el manejo de las ONG mejor organizadas está claro cuánto pueden modificar estas comunicaciones horizontales las inercias con que las macroempresas y los Estados reproducen la hegemonía y las desigualdades. La asimetría en el acceso a la cultura de países centrales y periféricos se acentúa en las tecnologías de avanzada. Las redes de internet en las que algunos ven una oportunidad de incrementar la participación social, según datos de mediados de 1998, cuentan en Estados Unidos con más de 20 millones de hosts (sitios desde los cuales se difunde la información), en tanto los dos países latinoamericanos con mayor participación son Brasil con 117,200 y México con 41,659. Mientras una quinta parte de los estadounidenses son usuarios de la red de redes, los países latinoamericanos que más la usan no alcanzan a incluir al 2 por ciento de la población. Estos datos tienen que ver con diferencias de nivel educativo, el costo diez veces menor del servicio en Estados Unidos y el hecho de que 70 por ciento de los textos está en inglés y apenas 1.78 por ciento en español (Trejo Delarbre).

\section{Medios, cultura y calidad de vida}

Para desarrollar un pensamiento crítico sobre las transformaciones de lo público suscitadas por las nuevas tecnologías es necesario situarlas en sus condiciones sociales de producción, circulación y recepción. O sea que debemos replantear ciertos modos maniqueos de pensar lo social en los que lo público se oponía tajantemente a lo privado, y se acompañaba con disyuntivas 
igualmente esquemáticas entre Estado e iniciativa privada, entre lo nacional y lo foráneo.

Como un ejemplo de lo que es necesario reformular, voy a ocuparme de dos nociones básicas del pensamiento moderno: el interés público y la calidad de vida. Ambas son redefinidas bajo la globalización, y como consecuencia los Estados encuentran dificultades para ocuparse de ellas. Una dificultad para encarar la nueva situación reside en que el interés público y la calidad de vida suelen definirse por los contenidos. No quiero repetir la inconsistente división entre contenido y forma, pero debo hablar de contenidos porque gran parte de las apologías de la cultura nacional se asientan en una sobrevaloración aislada de ese aspecto. Escuchamos todavía que las principales razones para proteger el cine y la televisión nacionales serían que hablan de temas «propios» y narran historias «nuestras». La convicción de que los pueblos necesitan afirmar su identidad se vuelve el núcleo argumental en las defensas de la producción audiovisual de cada país, y se supone que los medios masivos «nacionales» serían los más capacitados para representar la propia cultura y las necesidades de los ciudadanos de cada nación.

No es este el modo en que aparecen interpretados el interés público y la calidad de vida por los espectadores. Al hacer estudios sobre consumo de cine, televisión y vídeo, he visto que los públicos tienden a comprender el interés público y la calidad de vida (en este ámbito del consumo) de un modo diferente al pensamiento ilustrado moderno. Los espectadores estiman públicamente valioso aquello que mejora sus condiciones de acceso y disfrute de los bienes culturales. No son los contenidos lo que aparece en primer lugar en sus valoraciones. Tampoco son cuestiones formales, si las caracterizamos de acuerdo con la estética culta: por ejemplo, la innovación del lenguaje o la experimentación narrativa de las películas y los programas televisivos. El aprecio de la mayoría de los espectadores se dirige más bien a la calidad técnica de los medios de comunicación, su espectacularidad audiovisual (que se apoya en esa competencia técnica), la confortabilidad del acto de consumo y el placer que una historia bien narrada, con ritmo y acción, proporcione a sus disposiciones estéticas rutinarias. Estas disposiciones estéticas no se arraigan exclusivamente en la cultura nacional. En un mundo donde predomina desde hace décadas la cultura estadounidense en las pantallas de cine y de televisión, el gusto mediático ha incorporado la iconografía y los modelos efectivos e intelectuales de ese país, tanto en las audiencias masivas como en las de mayor nivel educativo (García Canclini 1998). 
¿Qué consecuencias tiene esto para las políticas culturales? Nos conduce, por una parte, a dar más importancia a lo que los sectores masivos entienden por interés público en relación con la calidad de vida. Sin embargo, este asunto se vuelve problemático cuando registramos de qué manera los medios se vinculan con estas expectativas de las audiencias, Varios estudios de los años noventa describen la reducción de la cultura pública a la búsqueda del lucro privado, del debate sobre los dramas sociales a su intensidad momentánea y a una obsolescencia programada (Martin Barbero, Sarlo).

Pero también llama la atención que en Ias políticas estatales de todos los países se practique, en sentido opuesto, la misma escisión entre cultura y medios. Al considerar que los poderes públicos deben ocuparse sólo del patrimonio histórico, el arte y la literatura son dejados la televisión, la radio, los videos y la informática bajo el dominio de empresas privadas. Salvo unas pocas radios y estaciones de televisión culturales, y acciones cada vez más débiles de estímulo al cine, las acciones públicas prácticamente están ausentes ante las audiencias masivas.

Cuando señalaba antes una asociación entre privatización, transnacionalización y desresponsabilización respecto de los intereses públicos estaba pensando en esta dificultad de los empresarios privados, librados a la simple lógica del mercado, para asumir las tareas públicas de la comunicación y el desarrollo cultural, y, a la vez, la desresponsabilización, respecto de lo público de parte de los Estados que antes se ocupaban más de la cultura «clásica», y no han desarrollado nuevas acciones respecto de la etapa de industrialización y transnacionalización de la cultura.

¿Qué podemos esperar en este proceso del Estado y de los organismos supranacionales (UNESCO, BID, OEA, Convenio Andrés Bello, SELA, Mercosur)? Estas instancias en tanto representan intereses públicos, pueden contribuir a situar las interacciones comerciales en relación con otras interacciones sociales y culturales donde se gestiona la calidad de vida y que no son reductibles al mercado, como los derechos humanos, la innovación científica y estética, la participación social, la preservación de patrimonios naturales y sociales. Los órganos estatales y supranacionales pueden operar como un conjunto de actores que reconoce que el mercado es insuficiente para garantizar los derechos sociales y culturales, las reinvindicaciones políticas de mayorías y de minorías. A diferencia de la oposición realizada en otro tiempo, entre el Estado y los organismos intergubernamentales, y por otro lado las 
empresas, hoy concebimos al Estado como lugar de articulación de los gobiernos con las iniciativas empresariales y con las de otros sectores de la sociedad civil. Una de las tareas de regulación y arbitraje que debe ejercer el Estado es no permitir que la sociedad civil se reduzca a los intereses empresariales, e incluso que los intereses empresariales se reduzcan a los de los inversores (como se propuso en el Acuerdo Multilateral de Inversiones).

Hacer políticas culturales y de integración en medio de las nuevas formas de privatización transnacional exige repensar tanto al Estado como al mercado, y la relación de ambas con la creatividad cultural y la participación social. Una de las inconsistencias del liberalismo moderno fue creer que la libre asociación de los individuos en el mercado generaría la creatividad y prosperidad de todos. En los últimos tiempos se tiende a trasladar al libre comercio internacional entre empresas esa potencialidad virtuosa. Así como se ha revelado infundada, y finalmente ineficaz, la pretensión del Estado de controlar la creatividad cultural, también debemos cuestionar la afirmación de que el libre mercado favorece la libertad de los creadores y el acceso de las mayorías. Pero esta disyunción moderna entre Estado y mercado se muestra insostenible no sólo en relación con los productores de arte y comunicación sino también con la manera en que hoy se concibe la creatividad sociocultural de los receptores.

Si la creación cultural se forma también en la circulación y recepción de los productos simbólicos ¿cuál es papel de las políticas culturales en esos momentos posteriores a la generación de bienes y mensajes? Después de las temporadas en que el Estado intervino a través de la censura y el «libre» mercado lo hizo mediante la segregación comercial de acceso, tal vez llegó el momento de averiguar cómo coordinar a ambos para que participen de modo más democrático en la selección de lo que va a circular o no, de quiénes y con qué recursos se relacionarán con la cultura, La privatización creciente de la producción y difusión de bienes simbólicos está ensanchando la grieta entre los consumos de las elites y de las masas: el 95 por ciento de la población está adscripto a las tendencias más elementales de la comunicación masiva transnacional a través de la radio y la televisión gratuita, mientras un 5 por ciento, conectado al desarrollo global a través de los satélites, las computadoras y otros recursos tecnológicos avanzados, conoce las innovaciones en el trabajo y en el consumo, y obtiene la información necesaria para tomar decisiones.

En tanto las tecnologías avanzadas facilitan la circulación transnacional, el abandono de los Estados de su responsabilidad por el destino público, y la 
accesibilidad de los productos culturales, sobre todo de las innovaciones tecnológicas y artísticas, está agravando la brecha. La reestructuración desregulada y transnacional de la producción y difusión de la cultura neutraliza mucho más que el papel del Estado: la misma pregunta por el sentido público de la creatividad y la pluralidad cultural. Las políticas dedicadas a reequilibrar la distribución de la información y el entretenimiento de calidad son decisivas para generar la participación social de todos los sectores, bien informados de las nuevas condiciones nacionales y globales en las que su acción tiene sentido y eficacia. Esta corrección de la dualización cultural puede hacerse con políticas estatales que regulen la acción de los medios e impulsando acciones societales, como la formación de organizaciones de televidentes a consumidores culturales, ombudsman de los medios masivos, etc. Si se aspira a «reemplazar la democracia pasiva por una democracia inteligente donde el ciudadano está ampliamente informado» (Kliksberg), es necesario que las relaciones entre medios y audiencias contribuyan a hacer inteligible la vida social y no sólo a espectacularizarla para espectadores pasivos.

\section{Propuestas políticas para la ciudadanía cultural y la participación social}

Cuando nos preguntamos qué cine y qué televisión queremos, estamos decidiendo qué clase de espacio audiovisual y de integración latinoamericana elegimos, y con qué otras regiones priorizamos la relación. Si estamos convencidos de que las industrias culturales son un instrumento clave para fomentar el conocimiento recíproco y masivo entre los países latinoamericanos, y con otras áreas, la renovación de la legislación, la profesionalización de la gestión cultural de creadores y receptores en estas decisiones deben ser partes prioritarias de las políticas culturales. Esta participación social, a través de organizaciones de artistas y consumidores culturales, y con el apoyo de esa figura aún escasa en América Latina que es el ombudsman, puede lograr que las diferencias culturales sean reconocidas, que aún los sectores históricamente menos equipados para intervenir en la industrialización de la cultura, como los países periféricos, los indígenas y los pobres urbanos, comuniquen sus voces y sus imágenes. Que no haya lugar en las políticas culturales sólo para lo que al mercado le conviene sino también para la diferencia 
y la disidencia, para la innovación y el riesgo, para elaborar imaginarios colectivos multinacionales y más democráticos.

¿Puede la creatividad ser objeto de políticas? En parte sí, pensando que los creadores no son, como suponían las estéticas idealistas, dioses que emergen de la nada, sino de escuelas de cine y facultades de humanidades y de comunicación, que necesitan editoriales, museos, canales de televisión y salas cinematográficas para exponer sus obras. Pero también porque la creatividad sociocultural implica a los públicos. Decir que los lectores y espectadores tienen la última palabra en la decisión de lo que merece circular y ser alentado resulta una afirmación engañosa en sociedades donde los Estados cada vez hacen menos por formar públicos culturales a través de la educación, con bibliotecas entendidas como depósitos de libros y casi nunca como clubes de lectura, sin acciones que faciliten un acceso más parejo a todos los bienes simbólicos.

Los actuales procesos de integración económica están ofreciendo mejores condiciones que en toda la historia anterior de América Latina para avanzar en la coordinación de políticas regionales y con otras regiones, Sin embargo, los acuerdos firmados y los que se están gestionando no asignan a la integración y el intercambio culturales el lugar que deben tener como contexto y sentido de desarrollo conjunto. Los cambios económicos y tecnológicos que condicionan el mero desarrollo cultural van a una velocidad que no es seguida por los cambios de las instituciones públicas. Los pasos más ambiciosos en esta dirección han sido dados por algunas empresas comunicacionales privadas, pero estas hacen muy poco para construir culturalmente el espacio público de la integración. Una acción más decidida de los gobiernos, los organismos internacionales y los movimientos socioculturales podría encarar, entre otras tareas, las siguientes, que sugerimos en la reunión sobre Industrias culturales e integración latinoamericana realizada en julio de 1998 en Buenos Aires con el auspicio del SELA, la UNESCO y el Convenio Andrés Bello.

a) Crear un Sistema Latinoamericano de Información Cultural. Su principal función sería reunir estadísticas confiables de todos los países de la región, que registren el desarrollo y las tendencias de las inversiones culturales (estatales y privadas) de los consumos (especialmente de industrias culturales) y de las percepciones interculturales (imágenes de los otros países de la región y del espacio euroamericano y norteamericano). Este Sistema documentará, además de estadísticas información reciente sobre avances tecnológicos utilizables en actividades culturales, legislación e iniciativas que con- 
tribuyen a incrementar el financiamiento público y mixto de programas culturales (exención de impuestos, creación de fondos de desarrollo artístico, libre circulación aduanal junto con control de tráfico y pirateo de bienes culturales). No habrá un efectivo espacio cultural latinoamericano mientras no dispongamos de mapas de los movimientos socioculturales que describan su estructura y sus flujos, que permitan entrever su potencialidad.

b) Promover la creación de dispositivos que articulen a los sectores estatales, privado y asociativo. Uno de sus objetivos será facilitar la coordinación de las inversiones de cada sector sobre las bases de diagnósticos de las necesidades socioculturales de la población. Estos diagnósticos correlacionarán la información sobre los consumos, los equipamientos culturales y las inversiones disponibles o potenciales para expandir la producción cultura endógena.

c) Promover estudios que permitan valorar el papel de las industrias culturales en el desarrollo a partir de una estimación cuantitativa de su contribución al empleo, a las exportaciones y a otras áreas del desarrollo socioeconómico, así como una valoración cualitativa de su aporte a la formación de una ciudadanía nacional y latinoamericana.

d) Realizar estudios comparativos de los mecanismos de financiamiento de la cultura en los países latinoamericanos, en Estados Unidos, Canadá y Europa con el fin de dar a conocer las modalidades más idóneas para fomentar la complementación de recursos públicos y privados. Este análisis buscará tanto difundir e intercambiar experiencias entre naciones como explorar posibilidades de cooperación y financiamientos internacionales de programas culturales: no sólo comparar experiencias como las leyes mexicanas de pago con especie y la ley Rouanet y otras brasileñas, sino expandirlas, para la cooperación internacional. Como ya se ha propuesto (Garretón, 1994), para que avance la integración cultural latinoamericana, es necesario establecer un Fondo Internacional de Producción y Difusión Cultural. Este Fondo podría constituirse con cuotas asignadas anualmente por los países para realizar proyectos multinacionales o de artistas o actividades que, no siendo sólo del país contribuyente, realicen aportes a su desarrollo artístico o comunicacional. Un antecedente valioso en esta dirección es el Fideicomiso para la Cultura México-Estados Unidos, creado con fondos privados y públicos de los dos países, que otorga todos los años, desde 1991, financiamiento para proyectos en bibliotecas, publicaciones, música, danza, museos, artes visuales, arte en los medios, teatro, estudios culturales y trabajos interdisciplinarios, con la condición de que sean binacionales. 
e) Promover la creación de Consejos Nacionales de Industrias Culturales, en los que participen especialistas de cada sector, de las empresas, de las universidades, del sector público y de movimientos sociales, con la finalidad de regular el funcionamiento de tales industrias. Esta representación diversificada es la única que puede propiciar una consideración adecuada del interés público y el reconocimiento de las formas particulares de expresión de la ciudadanía (nacional, étnica, regional) contenidas en cada nación.

Un último comentario. No imagino ninguno de estos proyectos necesitando nuevas estructuras institucionales complejas o pesadas, No hay excedentes presupuestales ni el apremio de los asuntos lo permite. Las tareas indispensables para salir del retardo de varias décadas en las políticas respecto de las industrias culturales requieren medidas urgentes y eficaces. Como cuando los gobiernos tienen que comunicarse rápido para enfrentar una catástrofe. Hay que estar muy distraído para no darse cuenta de que el cierre de centenares de editoriales y miles de librerías en las dos últimas décadas, la caída de la producción nacional de películas y discos, el deterioro del sistema escolar en todos sus niveles son señales de alarma de nuestra decadencia societal. Los nuevos signos de dinamismo económico y cultural -el aumento del consumo en algunos bienes comunicacionales, el acceso multiplicado mes tras mes a Internet, el rápido predominio de la videoinformación sobre la lectura- combinan aspectos positivos y otros problemáticos. Es inquietante que no tengamos datos suficientes ni estudios globales en marcha para discernirlo, o sea para conocer qué cambios están generando en el tejido de nuestras sociedades y en la interacción entre ellas. Los pocos avances logrados en este conocimiento se deben a que el sistema de investigación científica mejor en algunos países de la región durante los años ochenta y noventa, y, dentro de las ciencias sociales, hay un particular crecimiento de los estudios culturales. Pero esto no ha modificado las agendas públicas de las políticas culturales, salvo excepciones, y parece no ser información atractiva en la gestión de los acuerdos de libre comercio o integración regional.

El dilema decisivo hoy en las culturas latinoamericanas no es defender las identidades o globalizamos, sino integrar sólo capitales y dispositivos de seguridad o construir la unidad solidaria de ciudadanos y sociedades que reconocen sus diferencias. 


\section{Bibliografía: \\ Néstor García Canclini. \\ Industrias culturales y globalización: Procesos de desarrollo e integración en América Latina.}

Sealtiel Alatriste. «El mercado editorial en lengua española», documento elaborado para el seminario Integración Económica e Industrias Culturales en América Latina y el Caribe, auspiciado por el SELA, Ia UNESCO, el Convenio Andrés Bello y el Gobierno de la Ciudad de Buenos Aires, 30 y 31 de julio de 1998.

Gabriel Omar Alvarez. «Politicas regionales en el mundo de la globalización» documento presentado en el seminario antes citado.

Arjun Appadurai. Modernity at large: cultural dimensions of globalization, Minneapolis, University of Minnesota Press, 1996.

Lourdes Arizpe (ed.), The Cultural dimensions of global change, An anthropological approach, Paris, UNESCO Publishing, 1996.

Lluis Bonet y Libert de Gregorio. "La industria cultural española en América Latina», documento presentado en el seminario citado.

Manuel Castells. La ciudad informacional, Madrid, Alianza, 1995.

Manuel Antonio Garretón. «Políticas, financiamiento e industrias culturales en América Latina y el Caribe», documento de la $3^{a}$ reunión de la Comisión Mundial de Cultura y Desarrollo de la UNESCO, San José, Costa Rica, 22-26 de febrero de 1994.

Néstor García Canclini (coord.), Culturas en globalzación, América Latina-EuropaEstados Unidos: libre comercio e integración, Caracas, Nueva Sociedad, 1996.

"Cultural policy options in the context of globalization», en World Culture Report, UNESCO, 1998.
Nicholas Gamham. "The Media and the Public Sphere» en Craig Calhoun (ed.), Habermas and the Public Sphere, Cambridge, Ma. Mit. Press,

Ulf Hannerz. Conexiones transnacionales, Madrid, Cátedra, 1998.

John Keane. «Structural Transformations of Public Sphere», en The Communication Review. Vol 1, No 1, San Diego, 1995.

Bernardo Kliksberg. Seis tesis no convencionales sobre participación, mimeo.

Jesús Martín Barbero. Pre-Textos, Colombia, Centro Editarial Universidad del Valle, 1995.

Miquel de Moragas. «Políticas culturales en Europa: entre las políticas de comunicación y el desarrollo tecnológico», en Néstor García Canclini (coord.), Culturas en globalización. América Latina-Europa-Estados Unidos: libre comercio e integración, op cit.

Renato Ortiz. Mundialiçaçao e cultura, Sao Paulo, Brasiliense, 1994.

Rafael Roncagliolo. «La integración audiovisual en América Latina, Estados, empresas y productores independientes", en Néstor García Canclini (coord.), Culturas en globalización. América Latina-Europa-Estados Unidos.- libre comercio e integración, op. cit.

Beatriz Sarlo. Escenas de la vida posmodema, Buenos Aires, Ariel, 1994.

Raúl Trejo Delarbre. «La lnternet en América Latina", Informe presentado al seminario Integración Económica e Industrias Culturales en América Latina y El Caribe, 30 y 31 de julio, Buenos Aires, 1998.

UNESCO. Our Creative Diversity. Report of the World Commission on Culture and development, París, 1994.

George Yúdice. «La industria de la música en el marco de la integración América LatinaEstados Unidos», documento presentado en el seminario citado. 